\title{
Decentralized food systems and eating in localities: a multi- scale approach
}

\author{
Sistemas alimentares descentralizados e a alimentação nas localidades: uma \\ abordagem multiescalar
}

\author{
Renato S. Maluf ${ }^{1}$ (D)
}

${ }^{1}$ Programa de Pós-graduação de Ciências Sociais em Desenvolvimento, Agricultura e Sociedade (CPDA), Universidade Federal Rural do Rio de Janeiro (UFRRJ), Rio de Janeiro, RJ, Brasil. E-mail: rsmaluf@gmail.com

How to cite: Maluf, R. S. (2021). Decentralized food systems and eating in localities: a multi-scale approach. Revista de Economia e Sociologia Rural, 59(4), e238782. https://doi.org/10.1590/1806-9479.2021.238782

\begin{abstract}
This article describes a systemic approach to analyzing issues related to food and eating, starting with a review of the different meanings and uses of the notions of food systems and agri-food chains. A systemic, multi-scale approach is developed to support the proposed notion of decentralized food systems in an attempt to account for the complementarities, conflicts, and hybridisms that result from the coexistence of distinct food systems in terms of modes of production and distribution, flows of goods, and the shaping of eating habits. Special attention is paid to localities and respective territories as analytical spheres, with the introduction of empirical evidence from two studies conducted in the Brazilian localities of Juazeiro (Bahia) and Chapecó (Santa Catarina).
\end{abstract}

Keywords: food systems, food politics, food provisioning, family farming.

Resumo: O artigo trata da utilização do enfoque sistêmico na análise de questões relacionadas com os alimentos e a alimentação, iniciando com uma revisão de diversas acepções e usos das noções de sistema alimentar e cadeias agroalimentares. Propõe uma abordagem sistêmica e multiescalar com base na noção de sistemas alimentares descentralizados, buscando dar conta das complementaridades, conflitos e hibridismos resultantes da coexistência de sistemas alimentares distintos em termos de modos de produção e circulação, fluxos de bens e formação de hábitos alimentares. Atenção especial é dada às localidades e aos respectivos territórios como plano de análise. Referências empíricas são extraídas de duas pesquisas realizadas nas localidades de Juazeiro (BA) e Chapecó (SC)

Palavras-chave: sistemas alimentares, política dos alimentos, abastecimento alimentar, agricultura familiar.

Introduction

The concept of food systems is widely used to construct comprehensive and integrated approaches, from the production and circulation of food products up through consumption; these systems are commonly (and sometimes carelessly) referred to as a self-explanatory analytical resource. This article utilizes proposes an approach with essential systemic elements to analyze food and eating. The dual designation differentiates food products (food) and how they are utilized and consumed (eating) by individuals, families, or social groups, not only to avoid equating these two non-synonymous terms but rather so they can mutually complement and constitute one another. ${ }^{1}$ Looking at food or eating alone ignores the interconnections that provide fuller meaning to both; furthermore, the multi-scale nature of food systems and identify systemic determinants and tensions associated with a

1 This analytic formulation was inspired by Agamben (2017, p. 24). 
variety of aspects such as poor nutrition, eating habits, social inequalities, food corporations, and modalities of food production must also be considered.

Here the concept of the system itself is addressed, the degree of complexity implied when it is used as a focus, and in this case, the components of food systems and the interactions between these components and between systems. Misunderstandings or losses can occur when "system" is used to classify what is no more than a set of activities that are interconnected or linked together as chains or networks, or when the dynamics of a system are limited to the existence of multiple factors that mechanically work to determine processes or events. This essay develops a systemic approach in which food systems are complex ensembles determined by interdependent flows between their components, the evolution of which involves complements, conflicts, and contradictions, and consequently require public and private mechanisms to coordinate components of these systems that do not function harmoniously and may evolve in a variety of directions. This premise underlies the goals of analyzing the plurality of food systems on different scales and the coexistence between these systems, contributing to an approach to eating in localities and respective territories based on the concept of decentralized food systems and its implications for food provisioning.

A connection with the local or territorial sphere (which is quite usual in analyses of food and eating) seems mandatory to specify the links that are embedded in what is produced and what is eaten, particularly links with culture and environment. Josué de Castro, in his 1946 preface to Geografia da Fome, noted that the phenomenon of eating is best suited to ecological studies of the correlations between human groups, the regional frameworks (the environment) they occupy, and the processes by which populations organize themselves to satisfy their food needs, thus justifying the use of an ecological survey in this analysis of hunger. (Castro, 1992)

Nevertheless, food provision has assumed new dimensions as food production and circulation have been integrated into the international arena under the hegemony of big corporations, the complexity of medium-sized and large cities and metropolitan regions has been accompanied by transformed urban/rural relations in territories, and consumption patterns have changed, particularly eating habits that combine standardization and diversification. Additionally, criticism of the dominant patterns of producing, distributing, and consuming food has generated a broad spectrum of initiatives, alternatives which Goodman et al. (2012) describe as expressing the dispute for social control over the food provision which is reflected in food politics.

One conception of food provision that extends beyond conventional, restricted approaches to the physical availability and marketing of agri-food products can be found in Maluf (2017), who describes it as the diverse and complex set of activities in the sphere of circulation that mediate access to food and its production and involve a variety of social actors, most notably private economic agents and government agencies. This is also a multiscale task that implies differentiating food provisioning issues as they relate to national and international contexts (for example, international trade, large corporations, establishing prices, inventory management, modalities of agriculture, land occupation, income, and access) or to territories and locations (such as distribution and retail sales of food, availability and physical access, and streams or circuits of goods).

In terms of public policies and actions, this article adopts the precepts of food and nutrition sovereignty and security and the human right to adequate and healthy food, with the meanings attributed in the Brazilian social construction of these notions (Leão \& Maluf, 2012). Within this context, sovereign food provisioning policies encompass actions and instruments that promote expanded access to adequate and healthy food from socially inclusive, environmentally sustainable, and diversity-affirming forms of production and distribution.

The concept of decentralized food systems involves a multi-scale approach to food systems, extending into territories and localities to capture interactions between systems with different amplitudes, economic dynamics, social actors, and politics involved in the availability of and access to food and eating. In this way, decentralized food systems are how food is produced, circulated, and consumed in localities resulting from the intersection between 
local, national, or international systemic dynamics involving a wide variety of social actors, conflicts, and decision-making processes that also exist on multiple levels.

Finally, the concept of locality is intended as a socio-spatial reference that is not restricted to a specific spatial unit but rather describes a place and an imagined social space where events and situational encounters shape ways of life and the life of society, as conceived by Arce \& Long (2010). Even closer to the issues raised in this text, Carneiro (2008) proposes an understanding of locality which overcomes the rural/urban binary to refer to empirically referenced universes of specific social relations with components of identity that materialize in the relation with a space and a set of cultural symbols. To avoid the duality mentioned previously, the methodology used herein addresses localities as socio-spatial units delineated from the urban nucleus in which social actors and activities related to food and eating interact as relations of complementarity, substitution, and conflict, permeated with systemic dynamics of distinct amplitudes that exist in the respective territories. The main link between urban and rural, in this case, is established through food provisioning, whether this comes from the rural areas surrounding urban centers or far-off farms connected by farther-reaching agri-food chains; this link has the characteristics of a two-way street, although urban determinants predominate. The result is an approach that starts with food and eating before arriving at production and distribution, changing (when not inverting) the meanings that are commonly analyzed in agri-food chains and the possibilities of family-based, diversified agriculture.

Although this article is presented in the form of an essay and is not based on a specific field survey, some data is included from recent research in Juazeiro, Bahia, and Chapecó, Santa Catarina. ${ }^{2}$ While these studies investigated other questions, the findings illustrate the connection between the formation of eating habits, the composition of menus for urban and rural families, and the coexistence of food systems involved in provisioning these localities. Although this is not a comparative analysis, the differences in socio-spatial contexts can also be useful.

Juazeiro is located in the heart of Brazil's semi-arid Northeast ${ }^{3}$ and has faced profound changes in the production, distribution, and consumption of food, with marked socioeconomic and environmental contrasts reflected in its landscape (Luz \& Maluf, 2019). ${ }^{4}$ At the same time, a "food movement" that links social organizations and government agencies adds complexity to food politics in this region, which has a strong cultural heritage related to eating, circles of proximity, and small farmers (Luz \& Maluf, 2019). The city of Chapecó is also a regional center, but in a temperate climate in the south of the country. Large agri-food industries and capitalized farmers are present, many descended from Italian and German settlers. ${ }^{5}$ Migration to the city, the arrival of "outside agents," and the interconnection between urban and rural is reflected in the population profile and eating habits. Of course, the framework of inherited and assimilated habits is more complex, given the influence of private agents led by the food industry and retail networks and supported by intense propaganda, all widespread in Brazil. Nevertheless, social actors have mobilized around the issue of food in the Chapecó region, highlighting the association between local food culture and family-based diversified agriculture, similar to Juazeiro. Some shared

\footnotetext{
${ }^{2}$ The fieldwork in Juazeiro received support from the project Towards food sustainability: reshaping the coexistence of different food systems in South America and Africa (CDE, University of Bern), while the research in Chapecó was part of the project Gouvernance alimentaire et pratiques des ménages agricoles: une approche par les flux d'approvisionnement alimentaire et la multi-localisation familiale (GloFoodS, INRA/CIRAD).

${ }^{3}$ The city of Juazeiro is the main urban center in the Sertão do São Francisco territory, which resulted from a territorial development policy encompassing ten municipalities in an area of $61,778 \mathrm{~km}^{2}$. Approximately 520,000 people lived in this region in 2007, 44\% concentrated in Juazeiro (Lasa \& Santos, 2008).

${ }^{4}$ Landscape is not only a resource for graphic description, but also a representation of particular forms of geographical vision (Cosgrove, 2008). Josué de Castro titled one of his books Geografia Humana: um estudo da paisagem cultural do mundo [Human Geography: a study of the world's cultural landscape]. Additional work is needed to further develop the notion of food landscape.

${ }^{5}$ With an estimated population of 216,654 in 2018, Chapecó has experienced rapid population growth and intense urbanization in recent decades, with more than $90 \%$ of the population residing in an area considered urban. It is classified as an intermediary municipality that serves as a center for rural western Santa Catarina, a mesoregion with 118 municipalities and approximately 1.6 million inhabitants (Instituto Brasileiro de Geografia e Estatistica, 2017).
} 
characteristics in these two regions permit discussion of the components of food politics that are present throughout Brazil, along with their respective local particularities. Family farming, as an important route for food culture in both territories, also creates a powerful argument to value its role in food provisioning, but the systemic focus must be applied correctly to understand the contexts and how this value could be created.

The following text is divided into three sections, in addition to this introduction and final remarks. The first section briefly reviews appropriations of the systemic approach and conceptions of the food system which are present in the specialized literature. The second section presents the concept of decentralized food systems, which results from the multiscale perspective and is a reference in the territorialized analysis of food supply. The third section introduces the political dimension of food provisioning, a central component of food politics with implications for the analysis of food systems.

\section{About food systems}

The emergence of the systemic paradigm reflects the perception that reality involves a set of interconnected and interdependent elements, and consequently requires analytical instruments and interventions that are compatible with this premise (von Bertalanffy, 2008; Capra, 2003). ${ }^{6}$ Following initial steps in the natural sciences, particularly physics and biology, systemic thinking has been incorporated into the humanities and social sciences to analyze social systems in different directions. It was first appropriated by Pareto (1917), who applied mechanistic logic and the equilibrium hypothesis to explain successive states of a social system; this analytical method still endures and will be contrasted herein. Another early and more pertinent notion is the view of active social systems, which Parsons (1951) used to analyze the interaction between individual actors from a systemic and relational perspective. The "passage" of a systemic focus from natural to social science has resulted in recent developments around the inseparable connections between nature and society, mainly in approaches to food systems. Some formulations view eating as one of the strong links connecting human health and ecology (Rayner \& Lang, 2012), while others suggest assessing food as part of common assets (van Laerhoven \& Ostrom, 2007; Vivero-Pol, 2017). As Santos has stated (Santos, 2001), the systemic approach helps to establish "non-dualistic" visions of the world in social sciences.

In the approach used here, social systems related to food and eating are part of complex ensembles of inter-relations between their components that evolve into contradictions, with conflict and imbalance in systemic relations present in economic, social, and political dynamics (Burlandy et al., 2006). ${ }^{7}$ This has led to the understanding of food systems that are open to various possibilities and function in a non-harmonious manner, ${ }^{8}$ with two main justifications. First, supposing that systems are open means considering the reflexivity of the processes through which food politics is constructed and affects these systems. Second, systemically interdependent flows are considered to result in unbalanced or unbalancing dynamics that catalyze social structures (Hirschman, 1977), ${ }^{9}$ a premise that implies a departure from any assumptions of circular flows, closed solutions, or models of equilibrium.

\footnotetext{
${ }^{6}$ von Bertalanffy (2008) defines a system as "a complex of interacting elements," a whole which cannot be separated into independent parts with properties that none of the parts has, and consequently defines all organized wholes as compositions and not mere aggregates (Prado, 2011). Capra (2003) maintains that systemic thinking is more than holistic, since it addresses the parts as well as the whole in "contextual" and "procedural" thinking.

${ }^{7}$ Meanwhile, Burlandy et al. (2006) describe a pioneering reflection in two distinct but connected spheres that use the systemic focus as an analytical instrument and an organizational principle of food and nutrition sovereignty and security policies.

${ }^{8} \mathrm{~A}$ perspective that differs from Bertalanffy's general theory of systems and its multivariate mathematical solutions with complex mechanisms present in ecosystems and social, economic, and political systems (Prado, 2011), as well as the open systems described by Capra (2003) which feature self-regulation as a key property and assume that systems are (nearly) static.

${ }^{9}$ For Hirschman (1977), the interrelationships between linked activities result in an unbalanced and non-harmonious social assembly driven by mechanisms that induce decisions by agents at various stages in these chains. Rather than a problem, creating imbalances makes the social structures more dynamic.
} 
There are systemic models with varying degrees of complexity; it is sufficient to characterize and define food systems by the existence of interdependent flows and private and public coordination mechanisms between components of the respective system (Burlandy et al., 2006). "Interdependent flows" are based on linkages where symbiotic relationships, interactions, and synergies constructed by the action of the system's components occur. They promote both the systemic propagation of strategies used by private agents (large corporations) and demand trends, as well as the equally systemic repercussions of actions by factors that extend beyond the respective system, such as price formation or public policy initiatives.

Meanwhile, coordination mechanisms result from the complementarities, tensions, and conflicts that are characteristic of relations between economic agents and social actors in general, which may or may not be impacted by government regulation; they may also reflect specific public policy objectives. Types of mechanisms vary, with accordingly different formats and modes of operation. Market mechanisms are viewed by standard economic theory as the most efficient and sufficient coordination instrument for guiding private economic decisions via what is known as the price system. Here systemic coordination is considered to manifest as mechanisms or spaces that can express interaction, complementarity, and also horizontal and vertical conflicts between private agents and their relations with government authorities. Other spaces and mechanisms include various types of associations, sectoral committees, social networks, and spaces for participation in public policy, coexisting with the coordination ability of private initiative, which provides agents on the scale of distribution networks and large agribusiness.

In summary, systemic dynamics involve interdependence, complementarities, and conflicts between the components of the systems, which consequently operate in an unbalanced manner that is open to various solutions, and the notion of the system should not be associated with circularities, automatisms, or harmonious operation. Furthermore, the non-reductivist underpinnings of systemic reasoning signify that meaning is derived from the interrelationships between the parties (Prado, 2011), in such a way that use of the concept of food systems requires the presence of this "all-encompassing" role played by food and eating in the approach proposed herein. In these terms, food systems are more than the mere aggregation of a set of interconnected activities and do not permit unclear or interchangeable usage of systems and chains. Typical analyses of agri-food chains and agribusiness complexes tend to focus on the linkages between activities related to the production, distribution, and consumption of food, and while they offer the advantage of not segmenting analysis, they lend themselves to different purposes. ${ }^{10}$

The proposal is consequently to define and characterize food systems based on food and eating as the center of observation which sheds light on the actors, processes, and tensions that shape food politics, based on a multi-dimensional and multi-scale approach. Systemic dynamics are located within social formations from which social relations, economic activities, and conflicts are derived, in such a way that the backdrop to the analysis of food systems is the place of food and eating within the broad spectrum of capitalism. In the case of Brazil, this variety of capitalism is rooted in profound social inequalities with strong and long-standing economic and political influence from large-scale food production and the agribusiness sector.

Other research has addressed the existence of a food question in countries' development that involves business, power, basic needs, and human rights, founded on the social, economic, and political importance of food access, availability, and consumption (Maluf, 1998). Even so, this argument should also include food and, consequently, agriculture as important components of the accumulation of capital and sources of power, as seen in the focus on food regimes (Friedman \& McMichael, 1989; McMichael, 2009). The approach to food systems then becomes an analytical instrument that assists in analyzing manifestations of the food question in capitalist development. In these terms, the mechanisms of systemic coordination, which do not have any meaning in promoting

${ }^{10}$ To Louis Malassis (1983), a pioneer in the use of the concept of chains (filières) in the field of agriculture and food, food systems must be analyzed considering strong intersectoral relationships within the agri-food complex. 
harmonic and circular dynamics, come to be seen as part of the regulatory instruments that are essential considering the conflicts intrinsic to capitalism, as indicated from the viewpoint of social regulation (Boyer, 2009), where tension is always present between public and private regulation (Harris-White, 1996). From a normative perspective, there is a notable difficulty in making intentional development consistent with immanent processes of capitalist development (Cowen \& Shenton, 1996) which is seen in the tensions and conflicts surrounding the promotion of modes for producing, trading, and consuming foods through strategies for equitable, sustainable, health-promoting development that also value cultural and environmental diversity.

At this point, some foundations for and applications of the systemic focus in the literature should be referenced to clarify aspects of the proposed approach to food systems. In the groundbreaking definition of Louis Malassis (1993, p. 7), "A food system is a set of coordinated activities that allow people to feed themselves. It is also how people organize themselves in space and time to obtain and consume their food." This synthetic and apparently simplified formulation has its merits, starting from eating and human agency to encompass a larger number of variables that explain the various forms of producing, accessing, and (to a lesser extent) consuming food, while also including the dimensions of space and time. The ability to apply the concept of food systems to such distinct circumstances as the family/household, localities, regions and even national and global scales is implicit; however, this undifferentiated usage limits the systemic focus's scope of analysis to interconnected sets of components or activities, even though this helps overcome the segmentation of approaches.

The correspondence between "food production systems" and certain forms of social organization reflected in the tendency toward complex technical and social structures of a capitalist nature and growing division of social labor led Malassis (1993) to differentiate artisanal, cooperative, and capitalist sectors. The conceptual development proposed here takes a slightly different approach by considering that human agency related to food and eating in a capitalist society is pervaded by hegemonies and conflicts defined within the spheres of politics (power) and the economy (the logic of capital), which affect how various food systems operate and coexist. In line with Malassis, the conceptualization of food systems by Rastoin \& Ghersi (2010) adds three important aspects to the satisfaction of human needs: networks of actors in the formatting of systems, the idea of interdependence or linkage, and correlation with a particular geographical area.

The precursor to attempts to "spatialize" or "territorialize" the approach to food systems was "localized food systems" (LFS), which associate the characteristics and operations of organizations of production and services with a specific territory, a combination that produces a type of agri-food organization on a certain spatial scale (CIRAD, 1996). According to Requier-Desjardins $(2002,2007)$, this concept bears similarities to those involving clusters and makes LFS an agri-food type of local production system, essentially based on qualification by the territorial origin and the competitive effectiveness of organizations anchored in the territory. In Brazil, this approach led to the creation of the Brazilian Network of Localized Agri-Food Systems, which focuses on strengthening local resources based on the relationship between agri-food systems and territories and their contributions to public policies. ${ }^{11}$ In closing, the notion of "territorialized food systems" should also be mentioned; this component of LFS incorporates material and immaterial values from the territorial focus and is directly connected to the objectives of food security and sustainability (Rastoin, 2014). Although they are comprehensive in the factors they consider (such as specific resources, modes of production, culture, and forms of governance), this type of anchoring exhibits a viewpoint that promotes the agri-food chains that exist in a given territory.

Here the perspective of "spatialization" which the systemic approach contains should be differentiated within the concept of decentralized food systems because although references to local or territorial systems are present, this multi-scale approach presupposes the coexistence of systems with distinct amplitudes whose very existence complicates the reality of localities and regions. It should also be noted that the multi-scale perspective is

\footnotetext{
${ }^{11}$ See http://redesialbrasil.blogspot.com/p/o-conceito-de-sial.html.
} 
preserved at the level of the localities and regions where interlaced dynamics of production and distribution and food consumption trends are expressed, in international, national, and sub-national (regional, territorial, or local) spheres.

Besides being differentiated according to scale or spatial amplitude, food systems can be differentiated by the nature of the goods or processes that generate food, a methodology that risks an undifferentiated use of the notions of systems and chains. This is the case for the five ideal types of food systems proposed by Colonna et al. (2013), which are named according to the types of products and production processes: agro-industrial systems (long chains of production and consumption); regional systems (small and medium-sized producers which are part of broader networks); domestic systems (most production for selfconsumption); local systems (informal market, artisanal, short circuits of production and consumption); different-quality food systems (agroecological, healthy, organic). In defining systems in a closer correspondence to chains, circuits, or even market segments, this criterion allows Morgan et al. (2006) to associate each of these five categories with worlds that contain their conventions and markets, ${ }^{12}$ with distinct combinations of different systems depending on the country, region, and locality.

Since food and eating are the gateway to the food system approach proposed herein, the diverse group of food products that comprise how people eat should be addressed. First, diet is known to be determined by various factors including income/social class, cultural habits, food standards, and characteristics of the respective ecosystem. Eating also involves correlations between the components of respective sets of goods, since a food product is rarely consumed (acquired) without a connection to other products, a premise that makes it impossible to consider goods or products separated from the whole, as is common in conventional economics and analysis of agri-food chains. The systemic approach should also incorporate biological, economic, and social complexities, as well as the symbolic dimension involved in interactions and circuits where food is involved since food is largely responsible for the material survival of a society, a strong and central link in the web of subjectivity in localities (Burlandy et al., 2006).

Also noteworthy is the approach by Fine et al. (1996), in which food systems are formatted from the meanings associated with food consumption; in other words, food systems are organized into systems of provision that vertically comprise chains of activities and meanings, differentiating themselves according to the groups of food they bring together. They emphasize the crucial significance of organic factors in both extremes of these systems, namely in production and consumption, and food norms are imposed on consumption in terms of connections between groups of goods with bonds based on underlying social and historically contingent relations. Meanwhile, for Barthes (1961) the meaning of eating and factors that explain its composition is defined in the orbit of its transformation and consumption, but not production since food (that which is eaten, nourriture) is a system of communication that constitutes a sign, alongside its primary biological function. The units of this communication system brought together in the "spirit" of food (a coherent set of food traits) rarely coincide with the food products that the economy usually addresses, and give rise to a general regime of tastes and habits. A return to Barthes' early idea of menus as "syntax" systems (1961) is interesting here; alongside regimes ("style" systems), these syntax systems lead to the semantic appearance of meanings from the communication system (food). This concept will emerge again later on in the use of inhabitants' menus in localities as a reference for analyzing prevailing eating habits. ${ }^{13}$

\footnotetext{
${ }^{12} \mathrm{~A}$ growing number of approaches are derived from convention theory in analyzing issues related to food and eating. See the approach to food orders by Niederle \& Wesz Junior (2018).

${ }^{13}$ Barthes (1961) was also one of the pioneers of the notion that once needs are met, nutritional value gradually loses importance in terms of the protocol value of food (in eating).
} 


\section{Conceptualizing decentralized food systems}

As defined above, decentralized food systems are how food is produced, circulated, and consumed in localities resulting from the intersection between dynamics and the local, national, or international level, involving a wide variety of social actors, conflicts, and decision-making processes that also exist on multiple levels. This characterization emphasizes the role of urban dynamics in the composition and articulation of how food goods are produced and circulate, particularly food consumption and access habits among inhabitants in localities. The goal is to consider the food politics involved in the complex set of actors and activities that comprise food provisioning. No less important, relevant sociocultural dynamics originating in the countryside integrate the city/countryside relationship here understood as a two-way street in many of the aspects involved in eating., despite the determining role played by industry, large-scale retail, media, and consumers themselves in shaping eating habits.

By starting from food and eating to arrive at the position occupied by agriculture and the rural world in food provisioning, this approach differs from notions of the food system that prioritize agriculture and start from the sphere of production to depict food systems. Food provisioning then becomes an "endpoint," or more properly, an offshoot of analyses of the chains, circuits, or networks that extend from the country to the city. Food systems, agrifood systems, and agro-industrial systems become almost synonymous; systems, chains, circuits, and networks are also confused. From another angle, economic dynamics and essentially urban sociopolitical dynamics grant food provisioning systemic complexity, although the category "urban" contains elements of its rural surroundings. This same reading is applied in addressing how various forms of family-based diversified agriculture are located within decentralized food systems and their place in supplying localities.

The view summarized in the previous paragraph has received new contributions, which result in focuses more closely approximating the approach proposed herein. These can be seen in the Brazilian version of the International Conference on Agriculture in an Urbanized Society (AgUrb), which was held in Porto Alegre in 2018, with a significant portion of the works discussed there gathered into a collection edited by Preiss \& Schneider (2020). Considering the centrality of food and assuming the context of urbanized societies are undoubtedly important steps in overcoming the focus on forms of production and circulation, even when addressing family-based production. Still, the ongoing use of agriculture as the starting point for analysis and the characterization of agri-food systems often make it difficult to go beyond the analysis of chains. In contrast, the systemic approach proposed herein uses food (and eating) as a starting point to arrive at agriculture and the rural, even while recognizing the presence of a two-way relationship.

The focus on decentralized food systems should also not be confused with the increasingly widespread notion of urban food systems (Wiskerke, 2015; Kasper et al., 2017), although some aspects are shared by both approaches. Driven by growth in various forms of urban and peri-urban agriculture, the focus on urban food systems has incorporated issues of distribution, logistics, and access to food in complex urban environments, the availability of healthy food, and even how environmental impacts and climate change resulting from the distant origins of many foods can be reduced. In the notion of decentralized food systems, the urban is referenced through the concept of "localities," and a spatialization criterion is adopted to emphasize the multi-scale dynamics that emerge between the determinants of food access and consumption, along with the ways of producing and distributing these goods. It should also be noted that its purpose is inextricably linked to explaining the social actors and conflicts involved in a local expression of food politics. Questions about how cities eat appear to be common to approaches in decentralized food systems and urban food systems, suggesting complementarity. Still, dialog with those who identify the impact of eating on people's lives and how cities are organized (Steel, 2008) would be more promising, since food and eating are used as a starting point (as in the approach proposed herein).

The scales of analysis (and, in turn, intervention) are a dimension that constitutes the decentralized food system approach since the food question takes on different 
characteristics according to how it refers to individuals and households, as well as national and global contexts. Analytical categories and intervention instruments specifically for each scale are required, while the interaction between scales generates relationships of reciprocal restraints and determination. The conditions of individuals and households in terms of food and nutrition reflect specific determinants as well as general factors; similarly, local actions directed at individuals and households have repercussions on the food and nutritional profile of the population as a whole.

The approach to food systems as well as food provisioning should also involve multiple scales, as an underlying justification for the decentralized food system approach and one of its motives, namely to assign a "place" to the local level and to use food and eating to describe the multiple systemic dynamics that interact there. Various factors or dynamics are defined at a national level, allowing the discussion of a national food system, just as others extend beyond national borders and correspond to a global food system, which is especially relevant for some products and the international organization of agri-food and industrial production. Both systems are promoted or supported by large corporations and by the governments of nations or blocs of countries. The composition and volume of aggregated supply and demand occur on national or international scales, as do connections between markets, the establishment of prices and stocks, trade flows, technical progress, means of communicating and forming eating habits, and formulation of public policy.

Circuits or flows with smaller spatial amplitudes and scales of operation (local, territorial, or regional) coexist with these national and international dynamics, rooted in local dynamics that presumably make them more inclined toward the circulation of less processed foods that are more in line with socio-environmental and cultural diversity throughout countries and their rural areas. This coexistence can lead to the concurrent presence of economic agents and channels in which many foods from different dynamics circulate, as seen in the predominance of supermarkets in distribution and retail sales alongside the (re)appropriation of the general characteristics of a national or global food system by local actors. Within the local sphere, food systems are defined with their own socio-economic, political, cultural, and ecological characteristics specific to each socio-spatial context, interrelationships, and combinations that are defined as decentralized food systems.

The coexistence of food systems implies the presence of different social actors, as well as certain roles for the government and public policies that extend beyond conventional regulatory functions to focus on the very shaping of these systems. In terms of food provisioning, without ignoring the questions specific to national and international contexts, the analysis addresses the particularities of food politics reflected in the "set of actors" surrounding the food question at the local or territorial level, but still does not imply any type of "localism." 14 Particular attention is paid to how diversified, family-based agriculture is inserted into multi-scale dynamics, due to their relevance to the focus on food and nutrition sovereignty and security adopted here. In most cases, localities correspond to medium-sized and large urban centers (cities), and the focus of observation then extends to the relevant territorial scope to understand the urban/rural relationship and the dynamics of food provisioning. ${ }^{15}$ The issues in small cities are different and include the influence of dynamics from larger cities or regional centers.

Here the premise is adopted that implementation of the food system concept always requires a spatial reference, which in this case is based on the spatial amplitude and degree of control or coordination for flows of goods and services that shape the respective food systems, consequently involving economic agents and social actors of certain types and scales of activity. By adopting the spatial criterion as the main differentiating factor that results in food systems on different scales, decentralized food systems constitute a type of

\footnotetext{
14 The relevance of the local dimension in provisioning politics corroborates the warning by Goodman et al. (2012) about the risks of "non-reflexive localisms."

${ }^{15}$ Friedman (2016) assessed food sovereignty in the region of Ontario, Canada based on the history of relations between cities and their rural surroundings, in two interwoven movements: agricultural transformations that took place in these neighboring areas, and eating habits among the inhabitants of expanding cities.
} 
arrangement among others that could be characterized, in this case to achieve a multi-scale approach to the provisioning of localities. Allowing multiple interlaced systems does not dilute the differentiation between system (as a multifaceted group full of tensions and conflicts) and chain (which contains inter-related steps by which goods are shipped).

The key point of the systemic focus on systemic relations located within interdependent flows and coordination mechanisms contributes to the scope and non-segmentation of the analysis of food and eating, considering the "whole" of systemic reasoning (as stated above), the meaning of which is derived from interrelationships between the parts (Prado, 2011). Additionally, Rist et al. (2016) concluded that assuming distinct food systems coexist with conflicts and even with trade-offs means assessing not just each system, but also the joint results of their interactions.

Overlapping flows of distinct goods and the presence of common agents can be identified by combining scale, product differentiation, and the interpenetration of agents centralizing nationally and internationally integrated chains and regional or local circuits (Maluf, 2004). Activities related to the distribution of food should be highlighted, particularly in the retail sphere in which the capacity of supermarkets to shipping a broad and diverse range of food products results in the centralization of respective flows of goods and reinforces the predominance of these markets in commerce and as a powerful instrument for relating to consumers. The arrival of regional and national supermarket chains in both of the locations surveyed (Juazeiro and Chapecó) exemplifies the restructuring of various mechanisms that comprise retail sales of food in the cities (a process that is widespread in Brazil), both direct sales to consumers as well as supply for traditional small retailers.

In Juazeiro, the greater availability and wider variety of goods are mainly explained by the city's integration into national and international circuits, the strengthening of a wholesale center, establishment of national and regional supermarket chains, and the advance of capitalized agriculture. In this region, specialized medium- and large-scale irrigated fruit farming coexist with large areas of sugarcane monoculture, and a significant number of family farms with diversified non-irrigated production adapted to the hot and dry climate of the Caatinga biome; public investments in social technologies (rural cisterns and electricity installation) have favored productive diversification of family farming involving goats, sheep, chickens, beekeeping, extraction of native fruit, and cultivation of beans, corn, cassava, and palm trees (Lasa \& Santos, 2008; Cezimbra, 2008). At the same time, social actors mobilize to promote access to "high-quality food" (traditional, agroecological, or organic items that are fresh and minimally processed) through a variety of activities based on the appreciation of the local culture.

The above-mentioned wholesale center in Juazeiro plays a significant role in food provisioning for that territory and other regions of the Northeast, as do companies that package and distribute semi-processed foods. At the same time, many of the foods produced locally on a smaller scale circulate through informal sales networks or are offered in sales outlets in the urban area, offering various means of provision, and local products as well as those from various regions in Brazil. However, the recent establishment of large supermarket chains, food distributors, and packaging operations in the territory has been the main vector for significant changes in how the population acquires food and eats (Luz \& Maluf, 2019).

In the case of Chapecó, the pattern of interdependence between the urban and the rural has been strongly influenced by large-scale agro-industry, and its links to a significant family-based agriculture contingent, an influence that remains even as urban activities have diversified (Fujita, 2013). In this way, habits have been preserved through family, cultural, or social connections with the rural environment such as European roots (Italian, German, and Polish) or Native heritage (Caboclos and Indians) (Tonezer et al., 2018), alongside new habits brought by people from other places and the diversification of urban activities. Like Juazeiro, Chapecó is an urban center that is sufficiently populous and diverse to permit the coexistence of distinct dietary practices and menus, combining national and international trends with old habits (whether those brought by European immigrants or descended from 
indigenous or Caboclo culture) along with new attitudes, beliefs, and trends that have also involved rural families for some time (Maluf \& Zimmermann, 2020). ${ }^{16}$

The predominance of supermarkets as a place for purchasing food and disseminating eating habits is not uncontested, nor does it extend throughout the entire spectrum of food products, many of which are traded at street fairs, public markets, bakeries, butchers, and small retailers in general, and particularly farmers' markets for family producers. These fairs and markets have clearly gained importance thanks to efforts by farmers, the community, and municipal governments (Fossá \& Badalotti, 2018), and they serve as an instrument for recovering the identity of foods in the direct relationship between producer and consumer (Cigognini et al., 2019) and for strengthening production by the farmers who sell at these fairs to feed themselves, with repercussions for their food and nutrition security (Pozzebom et al., 2015). This important aspect is permeated with the socio-spatial inequalities in the urban area, differentiating eating and purchasing habits between higherincome people who live in the downtown area and those who live in peripheral neighborhoods (Maluf \& Zimmermann, 2020).

The unifying role of food flows exercised by certain agents led Goodman et al. (2012) to question the term "alternative" when applied as a qualifier to food networks, considering the growing appearance of hybrids comprised of conventional and so-called alternative systems. This can also be seen in critiques of how the notion of system is used to differentiate chains according to the degree of processing or other metrics for the products that they move (agro-industrial systems, for example), or even to establish contrasts (such as traditional/modern or industrial/artisanal systems). Although it is important to contrast modes of production and standards of consumption, there is a risk involved in "slicing" economic agents, social actors, and consumers as if they were integrated into one system or another. After all, corporations individually manage portfolios of distinct products, family farmers tend to have a diversified list of crops, and consumers mix behaviors that result in hybrid diets.

As for mechanisms to coordinate the forms of public and private spaces that address the complementarities, tensions, and conflicts between components of the systems, some spaces and mechanisms may be specific or mainly dedicated to systemic dynamics with national repercussions (regulatory agencies, intersectoral or thematic committees and chambers, social participation councils) or international scope (international regulatory bodies). Meanwhile, in local spaces and mechanisms, the coexistence of multi-scale dynamics must be identified, including and especially when they address choices and strategies among agents on smaller scales that differ from the large-scale dominant factors in some way. Participation by entities and social movements which are directly engaged in production and marketing activities is a strong expression of food politics on this level and affects the format and function of various coordination mechanisms, particularly in contrast to the dominant dynamics. ${ }^{17}$ This framework is completed by the closer relations between these entities and organizations, along with those of private enterprise, government offices, and consequently with the implementation of public policies and mechanisms that support or regulate their activities.

To clarify, mechanisms and instruments of public coordination capable of fully addressing food systems (much less regulating them in a harmonious manner) are not presumed to exist at any of the three levels of government, an assumption which runs counter to nature and characteristics that have been attributed to food systems. Still, it is very important to identify such mechanisms and analyze their performance in applying the systemic focus and the decentralized food system approach, which intends to go beyond segmentation into chains and products or limiting the investigation to spatial criteria of local and territorial approaches when they are demarcated and analyzed individually.

\footnotetext{
${ }^{16}$ Increasingly unclear differences between how urban and rural families behave negate idealizations that contrast supposedly healthier habits among rural residents compared to those that prevail in the urban world. More and more urban residents are seeking out natural or healthy foods, while more industrialized/transformed products are being incorporated into the diets of rural households.

${ }^{17}$ The political spaces and events in Juazeiro in which social actors mobilize resources and form opinions on food issues include counsels, festivals, farmers' markets, and meetings. (Luz \& Maluf, 2019).
} 
Finally, in Brazil and almost all of Latin America, analysis of any relevant question must necessarily consider the high levels of social inequality. Therefore, a systemic analysis that emphasizes human activity (by social actors or economic agents) over technical or material connections (links and chains) leads to the perception that "how human sectors organize themselves to obtain their food" reflects and to a large extent reproduces the inequalities between them. This can be verified in the imbalance of power seen in economic dynamics and the appropriation of wealth in activities related to food and eating, through restricted access among those who cannot obtain food on a regular and adequate basis and consequently face poor nutrition and hunger. Resulting research questions include verifying how decentralized food systems reproduce the processes and dynamics that generate inequalities and restrict food production or access, as well as how social inequalities and poor nutrition itself are (or are not) visible and addressed in food policy in the local sphere.

\section{Eating, provisioning, and family farming}

The multi-scale approach to food systems and the notion of decentralized food systems extend into territories and localities to capture social actors and the politics involved in availability of and access to food and eating, and how eating habits are shaped within these socio-spatial units. This forms the backdrop for the analysis of food provisioning in localities, at the intersection between food systems on different scales, involving flows and interactions between a heterogeneous group of social actors, private agents, and public organizations and an intricate connection between local, regional, national, and international markets that mediates production and access to food (Maluf, 2017). The constitutive interaction of decentralized food systems simultaneously influences and reflects the combination of diets or eating habits (menus) in their respective localities; from another angle, they also depict food consumption habits and the corresponding forms of access to food as they encounter multi-scale dynamics composed of flows of products involving short circuits (local, territorial, or regional), intersected by national and even global flows of food production and distribution.

The solid economic assemblage formed by large-scale agri-food production, the food industry, and large-scale distribution is known to place limits on national food provisioning policies. The control large corporations hold over international flows, with the support of a few powerful nations or regional blocs, and the alleged role of the world food system in providing universal access to food are leading to strong and growing reservations about promoting the homogenization of productive processes and food consumption and the socio-environmental impacts of monoculture farming and large-scale livestock production. ${ }^{18}$ Additional factors are effective barriers to healthy eating in the face of lower pricing (which does not always result from competitive factors) for processed foods or those produced conventionally by large corporations (Heywood, 2013; Busch, 2010; Reardon et al., 2004), and the dwindling diversity of goods offered by the food industry due to the scale required to feed rapidly growing cities (Steel, 2008). Even worse, the relatively lower prices accompanied by the standardization of more accessible foods originate in and strengthen mono-crop agriculture and widespread use of chemicals and transgenics (International Panel of Experts on Sustainable Food Systems, 2016) as well as industry and its ultraprocessed foods (Louzada et al., 2015; Nestle, 2013), both of which involve high social, environmental, and health-related costs. This simultaneously results in pressures on the socalled alternative networks and places products with specific qualities outside the reach of most of the population (Goodman et al., 2012; Luz \& Maluf, 2019).

As anticipated, analysis of how these global and national dynamics unfold within a subnational (regional, territorial, and local) scope requires a multi-scale and reflexive approach of food politics and avoids idealizations that are common to localisms. ${ }^{19}$ Instead of assuming

\footnotetext{
${ }^{18}$ Proponents of this model cite the problematic notion of global food security based on international trade, which was never a trustworthy source of food security, much less food sovereignty.

${ }^{19}$ The limits of this essay prevent us from reviewing the reflexiveness of modern social life mentioned by Giddens (1991), or the cognitive and aesthetic meanings of reflexivity described by Lash \& Urry (1994); briefly, for Goodman et
} 
that just promoting local food systems and bringing production and consumption closer to each other ensure fairer, more egalitarian, or healthy food production, Goodman et al. (2012) propose a "reflexive localism" which sees food politics on the local level as reflexive and procedural, admittedly imperfect and associated with a concept of food justice that is equally reflexive. ${ }^{20}$ Local and democratic food politics should be founded on inclusive processes, correct the erasure of politics, difference, inequality, and social injustice, and counter normative certainties in such a way that the strategies and decentralized policies of provisioning and promoting sustainable food systems do not generate additional distinctions and inequities related to eating (Friedman, 2000; Goodman et al., 2012). The conventional focus on food policies then shifts to food politics by examining the actors, interests, and conflicts involved in open and conflicting processes related to food and eating, an analysis that encompasses public policies and respective programs and other government measures.

The procedural perspective helps us to understand the factors that make hybrid dynamics more common: these dynamics result from the strategies and actions that lead to interactions and even interrelationships between food systems. There is an apparent paradox that initiatives that add diversity to food provisioning and the diet of the population may go through the same chains or economic agents that are seen to compromise diversity; furthermore, national and even global chains play a role in accessing food that is not produced locally (due to lack of suitability or other reasons), even though they may result in the controversial standardization of habits. These dynamics can be observed from the complementary angles of the food provisioning flows and the shaping of eating habits.

On the one hand, contrasting chains and separate networks and differentiating the products that they circulate does not necessarily imply dichotomies, separate or dual worlds that get tangled in the sociopolitical characteristics specific to the social formations of their localities and the market strategies and disputes around provisioning. Specifically concerning the contrast between alternative and conventional, Goodman et al. (2012) identify interactions more than separated worlds, and the proliferation of hybrid expressions that create new and even more complex "worlds of food," at the same time that the dialectical process between market and social movements forces values such as social justice and ecological sustainability to coexist with the hegemonic capitalist system that seeks to adapt them to its strategies. Here is a good point for discussion, when a relational and procedural approach to how "alternative" forms of social organization can coexist and co-evolve with contemporary capitalist society is adopted; in this case, examining the limits of transformations that result when alternative values become embedded into conventional forms of food supply and global circuits of trade. In any case, reflexiveness and a procedural vision provide better analytical and conceptual accuracy in understanding how food networks are situated within food provision, in keeping with Marsden et al. (2000) and Morgan et al. (2006).

From a different and complementary viewpoint, confluences and hybridisms are present in the choices and composition of everyday meals among different social sectors of the population, and in the different circumstances in which foods are consumed. ${ }^{21}$ Eating habits are shaped by multiple factors, most notable disputes of narratives and commercial strategies which have not been addressed here, but which underlie these confluences and hybridisms. Also worthy of mention is the treatment of food standards that connect food

al. (2012, p. 30), reflexivity is not a set of values, but rather a process by which people pursue goals and recognize the imperfection of their actions.

${ }^{20}$ Food justice was originally introduced by urban movements in the United States, generally promoting social justice through food and emphasizing inequities that affect access to food (Gottlieb \& Joshi 2010; Clendenning et al., 2016).

Sen's notion of imperfect justice (2011) can be applied to the reflections on food justice by Goodman et al. (2012); Sen proposes overcoming or removing injustices that can be corrected or remedied based on "correct norms" and "socially appropriate behavior." The social changes necessary to deal with such iniquities are made through equally imperfect politics (Cadieux \& Slocum, 2015).

21 The research in Juazeiro revealed that even the dishes served at "food movement" events were influenced by a combination of local food culture and habits associated with global patterns, resulting in hybrid menus and traditional recipes prepared with processed ingredients (Luz \& Maluf, 2019). 
groups within the sphere of consumption, seen in Fine et al. (1996), and especially the vast contribution of studies on food culture. Although this literature cannot be addressed here in detail, it includes the diversity perspective which is so essential when dealing with food and eating. Cultural diversity was implicit in the ecological study by Josué de Castro ([1946]1992), from which aspects of adaptation to the environment (the semi-arid region) were derived, along with the construction of identities (sertanejo, in this case). Another dimension of diversity is presented by Declerck (2013), in relating the ecological diversity expressed in species diversity with food diversity and human health, concluding that the contemporary phenomenon of loss of ecosystem diversity results in the reduced nutritional quality of food, which is currently reduced to few species of animals and plants. This author notably observes that interactions between species are at least as important as the number of species for supply and stability of nutritionally essential functions.

The studies conducted in Juazeiro and Chapecó were not guided by the optics above, but some findings illustrate the combination of socioeconomic and cultural elements, territory, and ecological diversity in access to food and the forming of eating habits among rural families. In the case of Juazeiro and the Sertão do São Francisco territory, various initiatives to support production and consumption of locally-produced food came up against adverse climatic conditions during the worst drought seen in decades, while at the same time public actions led to significant changes in the living conditions of rural families (which were no different than those experienced by urban families). The strategies used to obtain food and the very makeup of eating for rural families have changed, since restrictions on their production of food have been accompanied by the increasing monetization of rural families' ways of living, greater access to public services, and close proximity to the cities. The availability of income provided by public transfers (such as the Bolsa Familia and Social Security social welfare programs) and programs to acquire food (PAA and PNAE) and electricity made it possible for rural people to purchase and consume industrialized and processed products. The determinants for incorporating these food habits include relatively low prices for industrialized processed foods compared with higher prices for traditional local products; in some cases, farmers sell nearly all of their production and purchase the food their families consume. Local menus feature traditional local foods and dishes such as goat meat, cassava flour, and corn couscous mixed with "generic" processed foods like bread made with wheat flour, chicken from large-scale producers, and sausage, with respect for local food culture accompanied by manifestations of more general trends in food consumption (Luz \& Maluf, 2019).

In the study of Chapecó and the neighboring municipalities, where activities and policies to promote local food culture are equally important, progress was made in measuring food diversity by having the agricultural families who were interviewed record their meals. This process led to a total of two hundred and ninety-seven varieties of food products and preparations consumed by these families; the variety of foods families produce is equally important for their consumption. Although food production and consumption were diverse in nearly all the categories of households interviewed, it was more pronounced in families that were part of shorter circuits and small-scale agroindustry (formal and informal), indicating that the diversity of food consumption in agricultural households is directly associated with the diversity of processes involving production, processing, and commercial relations maintained by these families. Confirming what has been said about the distinctive context of western Santa Catarina, even the less diverse diets cannot be described as "poor" in terms of calories or protein, since besides legumes and vegetables they include meat, which is generally considered to indicate better food access (Maluf \& Zimmermann, 2020).

In Juazeiro and Chapecó, family relations or links of sociability, in general, were seen to play a role in access to food or traditional dishes and products considered to be healthier, as observed in other regions. With this evidence, combined with the previously mentioned issue of relative prices, we return to the possibility that food with specific qualities (traditional, local, agroecological) may be accessed by consumers that are equally specific or differentiated, while consumption of these foods may be visibly lessened among the families that produce them and become prohibitively expensive to urban populations with lower 
purchasing power, or who are disconnected from the surrounding rural areas. In any case, there is no doubt that the relationship between urban and rural is essential in supplying populations in both areas, a two-way street that preserves old traditions and shapes new habits while also providing a source of food provision through purchasing, exchanges, and sharing. 22

Of course, this interconnected relationship depends on rural surroundings where family-based and diversified agri-food production still has a significant presence, a connection that may be at risk considering the trend toward more specialized, larger-scale agriculture inserted into national and international chains. This means losing the synergistic potential of physical proximity between producers and consumers, which in any case requires public action to be effective (Maluf, 2004). Landscapes that produce food can result from the principle of ecological diversity, or be affected by the predominant principle of productivity, which results in large areas covered with mono-crop farming alongside smalland medium-scale production of more biodiverse crops. The numerous works on short circuits of production, distribution, and consumption and their role in promoting sustainable rural development and healthy food explore the possibilities for inserting family-based agriculture into such circuits, and consequently into food provisioning itself. The premise that the circuits and dynamics of food provisioning interact, which has been adopted by the decentralized food system focus, questions the complex relationships that are established between social actors and economic agents in a network that is intertwined and often difficult to perceive. These interactions have been shown to lead to misleading and sometimes false absolute contrasts between conventional and alternative, local and global, natural and artificial, handcrafted and industrialized, in terms of ways food is produced and circulates.

Without ignoring the importance of valuing local dynamics and countering the critical aspects of so-called conventional models, noting the proliferation of hybrid forms and strategies in the literature (Goodman et al., 2012) does not make these local dynamics any less important in access to food and adequate eating. As for menus, there is a tendency toward standardization, whether this is the result of easier access to cheaper and lowerquality foods or changing lifestyles. But at the same time, local, traditional, and fresh goods acquire value, coexisting with industrialized and processed foods in daily meals, as noted by authors such as Morgan et al. (2006) and recorded in the studies conducted in Juazeiro and Chapecó.

\section{Final considerations}

The decentralized food systems approach provides a useful viewpoint for investigating interactions between multi-scale food systems, reflecting systemic determinants shaped on national and international levels and specific characteristics in terms of localities and respective territories. The procedure adopted for "scaling down" to the local level uses localities as a starting point for observation, then expands to encompass the relevant territory and analyze eating among its inhabitants, particularly aspects of the types and origin of foods consumed, the composition of menus, and means of acquisition. Localities and territories make up the scale of analysis in which the complementarities, conflicts, and hybridisms that result from or are associated with the coexistence of food systems become more evident, providing a better view of the manifestations of eating habits and respective menus in such a way that duly values socio-cultural and ecological diversity.

One outcome of the proposed approach refers to the criteria and main factors for characterizing and consequently differentiating decentralized food systems, without necessarily constructing an actual typology of these systems. The main elements of this characterization are related to the unique characteristics of the respective territories (the

\footnotetext{
${ }^{22}$ The "sitopic city" proposed by Steel (2008) (with "sitopia" representing the intersection of "sitos" (food) and "topos" (place)) would have a close relationship with its surroundings via food, with active markets and local shops, a strong sense of food identity, homes with large and comfortable kitchens, local schools teaching about food, and above all, the celebration of food.
} 
process of occupation and food landscape), socio-cultural profile, urban/rural relations, organizational density, and political/institutional milestones.

The premise that multi-scale food systems interact in decentralized food systems is mainly (but not exclusively) applicable to the analysis of food provisioning in various spheres. The multi-scale approach to food systems is also necessary to adopt references for food and nutrition sovereignty and security in actions and public policies, not only because these refer back to multi-dimensional objectives that require connected actions, but also considering the organization of systems of public policies (which in Brazil have led to the establishment of a national food and nutrition security system). Analytical use of the systemic approach cannot be confused with its use as an organizational model of the State, but additional research could address whether a system of public policies could encompass and have an impact on food systems.

Local/territorial and governmental/non-governmental initiatives are known to be important in terms of the production, circulation, and consumption of food, for example, the inclusion of family-based agriculture in the market and promotion of adequate and healthy eating, but the correlations between the various areas of system dynamics must be considered. Similarly, exploring themes of development raised by the ways that food is produced, distributed, and consumed in localities and territories (as is the case for promoting food production from diversified, family-based agriculture) implies considering dynamics with distinct amplitudes and economic agents of different sizes that intersect in localities and territories, with various degrees of repercussion.

This finally leads us to the question of food politics; like all the other aspects involved, its manifestations must be analyzed on the local and territorial levels in a way that is connected to how they are addressed in other contexts, especially (in this case) on the national level, where most conflicts around of food and eating come together. As mentioned earlier, care has been taken in this essay to avoid falling back on non-reflexive localisms with a perspective on food politics that seeks to characterize the "set of actors" surrounding the issue of the food reflected in choices, strategies adopted, and conflicts. One important component of food politics is that state and national food policies are locally appropriated or "translated" due to specific socio-political characteristics of the localities and respective territories, especially concerning how this set of actors and the power resources they can mobilize are established. Last but not least, this approach can be important in identifying public and private spaces where food politics manifest in the local and territorial spheres, the mechanisms and instruments of coordinating and coping with conflicts, and especially the aspect of social participation in a democratic environment.

\section{References}

Agamben, G. (2017). O uso dos corpos. São Paulo: Boitempo.

Arce, A. \& Long, N. (2010). The rise and challenges of an Anthropology of development. Porto Alegre: Wageningen University.

Barthes, R. (1961). Pour une psycho-sociologie de l'alimentation contemporaine. Annales. Économies, Sociétés, Civilisations. 16(5), 977-986.

von Bertalanffy, L. (2008) Teoria Geral dos Sistemas: fundamentos, desenvolvimento, aplicações. Petrópolis, $\mathrm{RJ}$ : Ed. Vozes.

Boyer, R. (2009). Teoria da regulação - Os fundamentos. São Paulo: Estação Liberdade.

Busch, L. (2010). Can fairy tales come true? The surprising story of neoliberalism and world agriculture. Sociologia Ruralis, 50(4), 331-351.

Burlandy, L., Magalhães, R., \& Maluf, R. S. (Orgs.). (2006). Construção e promoção de sistemas locais de segurança alimentar e nutricional: aspectos produtivos, de consumo, nutricional e de políticas públicas. Rio de Janeiro: CERESAN/UFRRJ. (Relatório técnico, n. 2)

Cadieux, K. V., \& Slocum, R. (2015). What does it mean to do food justice? Journal of Political Ecology, 22, $1-26$.

Capra, F. (2003) A teia da vida, uma nova compreensão científica dos sistemas vivos. São Paulo: Editora Cultrix. 
Carneiro, M. J. (2008). "Rural” como categoria de pensamento. Ruris, 2(1), 9-38.

Castro, J. (1992). Geografia da fome - o dilema brasileiro (pão ou aço). Rio Janeiro: Gryphus.

Cezimbra, C. (2007) Plano Safra Territorial do Território Sertão do São Francisco (BA). Salvador:

Cigognini, C., Piana, A. P., Santos, J. D., \& Bonamigo, I. M. (2019). A feira de produtos coloniais e agroecológicos de Chapecó: uma alternativa ao processo hegemônico de globalização no mundo contemporâneo? Chapecó: UNOCHAPECÓ. (Seminário Ruralidades Urbanidades).

CIRAD (1996). Systèmes agroalimentaires localisés (organisations-innovations et développement local). Montpellier, França: CIRAD/SAR.

Clendenning, J., Dressler, W. H., \& Richards, C. (2016). Food justice or food sovereignty? Understanding the rise of urban food movements in the USA. Agriculture and Human Values, 33, 165-177.

Cowen, M. P., \& Shenton, R. W. (1996). Doctrines of development. London: Routledge.

Colonna, P., Fournier, S., \& Touzard, J.-M. (2013). Food Systems. In C. Esnouf, M. Russel \& N. Bricas (Eds.), Food system sustainability: insights from DuALIne (pp. 69-100). Cambridge, UK: Cambridge University Press.

Cosgrove, D. (2008). Geography and vision - seeing, imagining and representing the world. London/New York: I.B. Tauris

Declerck, F. (2013). Harnessing biodiversity: from diets to landscapes. In: J. Fanzo, D. Hunter, T. Borelli \& F. Mattei (Eds.), Diversifying food and diets: using agricultural biodiversity to improve nutrition and health (pp. 17-35). Oxon, UK: Routledge.

Fine, B., Heasman, M., \& Wright, J. (1996). Consumption in the age of affluence - The world of food. London, UK: Routledge.

Fossá, J. L., \& Badalotti, R. M. (2018). Feiras Livres da agricultura familiar: desafios e oportunidades no município de Chapecó-SC. In Proceeding of the 3rd International Conference on Agriculture and Food in an Urbanized Society. Porto Alegre: UFRGS.

Friedman, H. (2000). Uma economia mundial de alimentos sustentáveis. In W. Bélik \& R. S. Maluf (Orgs.), Abastecimento e segurança alimentar: os limites da liberalização (pp. 37-63). Campinas: Unicamp/Redcapa.

Friedman, H. (2016). Food sovereignty in the Golden Horseshoe region of Ontario. In A. Wittman, A. A. Demarais \& D. Fields (Eds.), Food sovereignty in Canada - creating just and sustainable food system (pp. 169-189). Halifax\&Winnipeg: Fernwood Publishing.

Friedman, H., \& McMichael, P. (1989). Agriculture and the state system: The rise and decline of national agricultures - From 1870 to the present. Sociologia Ruralis, XXIX(2), 93-117.

Fujita, C. (2013). Chapecó: estrutura e dinâmica de uma cidade média no oeste de catarinense. GEO UERJ, 15, 24-1

Giddens, A. (1991). As conseqüencias da modernidade. São Paulo: Ed. UNESP.

Goodman, D., Dupuis, E. M., \& Goodman, M. K. (2012) Alternative food networks: knowledge, place and politics. London, UK: Routledge.

Gottlieb, R., \& Joshi, A. (2010). Food justice. Cambridge, MA: MIT Press.

Harris-White, B. (1996). Free market romanticism in an era of deregulation. Oxford Development Studies, 24(2), 27-45.

Heywood, V. H. (2013). Overview of agricultural biodiversity and its contribution to nutrition and health. In: J. Fanzo, D. Hunter, T. Borelli \& F. Mattei (Eds.), Diversifying food and diets: using agricultural biodiversity to improve nutrition and health (pp. 35-68). Oxon, UK: Routledge.

Hirschman, A.O. (1977). A Generalized linkage approach to development, with special reference to staples. Economic Development and Cultural Change, 25(Suppl.), 67-98.

Instituto Brasileiro de Geografia e Estatistica - IBGE. (2017). Classificação e caracterização dos espaços rurais e urbanos do Brasil: uma primeira aproximação (Estudos e pesquisas, n. 11). Rio de Janeiro: IBGE.

International Panel of Experts on Sustainable Food Systems - IPES-FOOD. (2016). From uniformity to diversity: a paradigm shift from industrial agriculture to diversified agroecological systems. Brussels, BE: IPES-FOOD. (Report \# 2).

Kasper, C., Brandt, J., Lindschulte, K., \& Giseke, U. (2017). The urban food system approach: thinking in spatialized systems. Agroecology and Sustainable Food Systems, 41(8), 1009-1025. 
van Laerhoven, F., \& Ostrom, E. (2007). Traditions and Trends in the Study of the Commons. The International Journal of the Commons, 1(1), 3-28.

Lasa, C. G., \& Santos, E. O. C. (2008) Plano territorial de desenvolvimento rural sustentável do território Sertão do São Francisco (BA). Salvador, BA.

Lash, S., \& Urry, J. (1994) Economies of signs and space. London: Sage Publications.

Leão, M. M., \& Maluf, R. S. (2012) A construção social de um sistema público de segurança alimentar e nutricional: a experiência brasileira. Brasília, DF: Abrandh/Oxfam.

Louzada, M. L. C., Martins, A. P. B., Canella, D. S., Baraldi, L. G., Levy, R. B., Claro, R. M., Moubarac, J. C., Cannon, G. \& Monteiro, C. A (2015). Alimentos ultraprocessados e perfil nutricional da dieta no Brasil. Revista de Saúde Publica, 49, 38.

Luz, L. F., \& Maluf, R. S. (2019). Social participation in political spaces and the valuing of culture as empowering resources to promote access to quality food in Brazil. Revue Internationale des Études de Développment, 1(237), 115-136.

Malassis L. (1993). Alimentar os homens. Lisboa: Instituto Piaget.

Malassis, L. (1983). Filières et systèmes agro-alimentaires. Economie et Sociétés, XVII(5), 911-921.

Maluf, R. S. (1998). Economic development and the food question in Latin America. Food Policy, 23, 155172.

Maluf, R. S. (2004). Mercados agroalimentares e a agricultura familiar no Brasil: agregação de valor, cadeias integradas e circuitos regionais. Ensaios FEE, 25(1), 299-322.

Maluf, R. S. (2017). Abastecimento alimentar, inflação de alimentos e o contexto urbano no Brasil. In R. S. Maluf \& G. Flexor (Orgs.), Questões agrárias, agrícolas e rurais: conjunturas e políticas públicas (pp. 179-193). Rio Janeiro: E-Papers.

Maluf, R. S., \& Zimmermann, S. A. (2020). Antigos e novos hábitos na alimentação de famílias agrícolas de Chapecó e região. Estudos Sociedade e Agricultura, 28(1), 48-77.

Marsden, T., Banks, J., \& Bristow, G. (2000). Food supply chain approaches: exploring their role in rural development. Sociologia Ruralis, 40(4), 424-438.

McMichael, P. (2009). A food regime genealogy. The Journal of Peasant Studies, 36(1), 139-169.

Morgan, K., Marsden, T., \& Murdoch, J. (2006). Worlds of food - place, power and provenance in the food chain. Oxford, UK: Oxford University Press.

Nestle, M. (2013). Food politics - how the food industry influences nutrition and health. Berkeley, CA: University of California Press.

Niederle, P. A., \& Wesz Junior, W. J. (2018). As novas ordens alimentares. Porto Alegre: Ed. UFRGS.

Pareto, V. (1917). Traité de sociologie génerale. Paris-Genève: Ed. Librairie Droz.

Pozzebom, L., Ludtke, R. C., Rambo, A. G., \& Gazolla, M. (2015). Repercussões territoriais das feiras de produtos coloniais e agroecológicos de Chapecó/sc: considerações sobre a SAN e o autoconsumo dos agricultores familiares. Santa Cruz do Sul, RS: UNISC.

Parsons, T. (1951). The social system. New York: The Free Press.

Prado, E. F. S. (2011). Complexidade e práxis. São Paulo: Ed. Plêiade.

Preiss, P. V., \& Schneider, S. (2020). Sistemas alimentares no Século XXI: debates contemporâneos. Porto Alegre: Ed. da UFRGS.

Rayner, G; Lang, T. (2012). Ecological public health: reshaping the conditions for good health. London, UK: Earthscan/Routledge.

Rastoin, J.-L. (2014). Les systèmes alimentaires territorialisés: quelle contribution à la sécurité alimentaire? Introduction (pp. 1-3). Paris: Académie d"Agriculture de France.

Rastoin, J. L., \& Ghersi, G. (2010). Le système alimentaire mondial: concepts et méthodes, analyses et dynamiques. Paris: Éditions Quae.

Reardon, T., Timmer, P., \& Berdegue, J. (2004). The rapid rise of supermarkets in developing countries: induced organizational, institutional, and technological change in agrifood systems. Journal of Agricultural Development Economy, 1, 168-183.

Requier-Desjardins, D. (2002). Les systèmes agroalimentaires localisés en Amérique Latine: un facteur de competitivité de l'agro-industrie rurale su des marchés globalisés. Economies et Societés, 25(910), 1421-1440. 
Requier-Desjardins, D. (2007), Systèmes agroalimentaires localisés et qualification: une relation complexe. Florianópolis, SC: UFSC. (Colóquio Internacional sobre Desenvolvimento Territorial Sustentável)

Rist, S., Golay, C., Bonanomi, E. B., Burgoa, F. M. D., Kiteme, B. P., Haller, T., \& Speranza, C. I. (2016). Towards food sustainability: reshaping the coexistence of different food systems in South America and Africa - Project description. (Working Paper, $\mathrm{n}^{\circ} 1$ ). Bern, Switzerland: Centre for Development and Environment (CDE), University of Bern.

Santos, B. S. (2001). Crítica à Razão Indolente: contra o desperdício da experiência. São Paulo: Cortez Editora.

Steel, C. (2008). Hungry City - how food shapes our lives. London: Chatto \& Windus.

Tonezer, C., Amaral, M. N., Cervini, S. F. M., \& Martinazzo, M. R. (2018). Identidade gastronômica: patrimônio imaterial do oeste catarinense. Geografares, 25, 238-262.

Vivero-Pol, J.L. (2017). Epistemic regards on food as a commons: plurality of schools, genealogy of meanings, confusing vocabularies. Basel (SW): Preprints.

Wiskerke, H. (2015). Urban food systems. In: H. Zeeuw \& P. Dreschel. Cities and agriculture: designing resilient urban food systems (pp. 1-25). London: Routledge/Earthscan.

Publicar rev 4/2021

submetido; $28 /$ may/2020

aceito: $5 /$ nov/2020

Classification JEL: P49 - Other Economic Systems: Other (Food Systems) 